\title{
RADIOCHEMICAL ANALYSIS OF CRUD \\ FROM THE ARMY PACKAGE POWER REACTOR
}

CONTRACT NO. AT(11-1)-318

By

J. L. Zegger

W. J. Small

w. S. Brown

Y

February 15, 1958

Alco Products, Inc. Post Office Box 414

1 Schenectady, N. Y. 


\section{4 \\ RADIOCHEMICAL ANALYSIS OF CRUD \\ FROM THE ARMY PACKAGE POWER REACTOR}

TABLE OF CONTENTS

Page

ABSTRACT

$\mathbf{v}$

I. INTRODUCTION 1

II. CONCLUSIONS 2

III. RECOMMENDATIONS 3

IV. EXPERIMENTAL METHODS 4

A. Sampling Procedure 4

B. Crud Removal and Dissolution Techniques 5

C. - Determination of Crud Weights 8

D. Radiochemical Procedures 11

V. DISCUSSION OF RESULTS 12

A. Specific Activity of Crud as a Function of Equivalent 12

Bull Power Hours $\quad 17$

C. Crud Level and Specific Activity 22

D. Deposited vs. Circulating Activity 24

v1. APPENDIX

DECONTAMINATION SCHEME FOR CRUD SAMPLES 27

VII, BIBLIOGRAPHY 


\section{ABSTRACT}

A study has been made of the radiochemical composition and the specific activity of insoluble corrosion products (crud) removed from the primary system of the APPR-1. This report presents the results of analysis of twelve crud samples collected during the interval from September 3, 1957 to December 1, 1957.

The samples were radiochemically analyzed for long-lived gamma emitting nuclides only. Data are presented on the measured values of the specific activity of crud, the ratios of the nuclide specific activities, and the concentration of crud (crud level) in the circulating primary water. Also included is data, based on the analysis of a single sample, comparing the specific activity of the deposited and circulating corrosion products. 


\section{INTRODUCTION}

An experimental program is in progress to obtain information on the buildup of long-lived radioactivity on the primary surfaces of the APPR-1. Quantitative measurements of the long-lived nuclides circulating in the coolant were first made during the 700 hour continuous performance test of the reactor (1). The experimental methods employed for that study measured the total activity of the coolant sample, with the results reported on a volume basis (dpm/ml of coolant). Consequently, the results of these initial measurements of the coolant activity were subject to the variation of the coolant solids level (crud level). Crud levels were not determined during the 700 hour test since crud sampling equipment was not inst alled in the system.

Investigations at WAPD have indicated that the major portion of the longlived activity is associated with insoluble material (crud) suspended in the coolant ${ }^{(2)}$. In order to obtain direct measurements of the activity of this insoluble material in the coolant of APPR-1, a suitable crud sampling device was installed in the primary purification system blowdown line. This report presents the data obtained from the radiochemical analysis of twelve crud samples withdrawn over the period from September 3, 1957 to December 1, 1957. 


\section{Conclusions}

1. The insoluble corrosion products (crud) obtained from the primary system of the APPR-1 contain the following nuclides: $\mathrm{Co}^{60}, \mathrm{Cb}^{58}, \mathrm{Fe}^{59}, \mathrm{Mn}^{54}$, and $\mathrm{Cr}^{51}$. These nuclides account for all the long-lived gamma activity associated with the crud.

2. The specific activity (dpm/mg) of these nuclides appears to be increasing with reactor operating time.

3. The specific activity of $\mathrm{Co}^{60}$ is accumulating faster than that of $\mathrm{Co}^{58}$ in the circulating crud. $\mathrm{Mn}^{54}$ specific activity is accumulating at about the same rate as that of $\mathrm{Co}^{60}$.

4. Uncertainties in the experimental data preclude defining a relationship between crud specific activity and crud level. 


\section{RECOMMENDATIONS}

1. Further investigation is necessary to establish the mechanism by which activity accumulates on primary system components, and to define the relationship between circulating activity and deposited activity.

2. It should be experimentally determined if a relationship exists between crud specific activity and crud level.

3. It is necessary to establish improved methods to accurately measure the concentration (crud level) of primary system insoluble material.

4. Measurements of the $\mathrm{Co}^{58} / \mathrm{Co}^{60}$ ratio should continue in order to establish the relative importance of cobalt impurities with respect to the nickel content of stainless steel. The possibility of $\mathrm{Co}^{60}$ arising from an n-p reaction on $\mathrm{Ni}^{60}$ deserves consideration. 


\section{EXPERMENTAL METHODS}

\section{A. SAMPLING PROCEDURE}

Figure 1 is a simplified flow diagram of the APPR-1 primary system showing the location of the crud sampling device. The sampling unit is a 4-1/2 inch long by 1-1/2 inch diameter micrometallic "PSS" type 316 stainless steel, hoilow cylindrical filter element, mounted within a 2 inch diameter stainless steel housing. The element is attached to the filter housing by means of a screw type insertion. Flow passes from the outside surface through the porous stainless steel into the hollow center, and out through the threaded connection. The element is rated to retain any particle larger than 2 microns. In collecting the first five crud samples, the filter was precoated with a fine spectrographic grade of graphite to increase filtering efficiency. However, difficulty was encountered in removing the graphite during subsequent treatment of the filters, and the precoating was eliminated when collecting the last seven samples. Flow through the filter was regulated by means of three needle valves. A positive displacement flowmeter with an accuracy of $2 \%$ was used to measure flow.

Sampling times were chosen to give a minimum of activity yet provide sufficient sample to permit accurate analysis. Approximately 65-70 gallons of water were passed through each filter over a period of several days. Upon removal of the filter element from the housing, the filter plus the water and crud contained in the housing were placed in a polyethylene container and shipped to Schenectady for radiochemical analysis.

\section{B. CRUD REMOVAL AND DISSOLUTION TECHNIQUES}

In preparation for radiochemical analysis of the crud, an effort was 


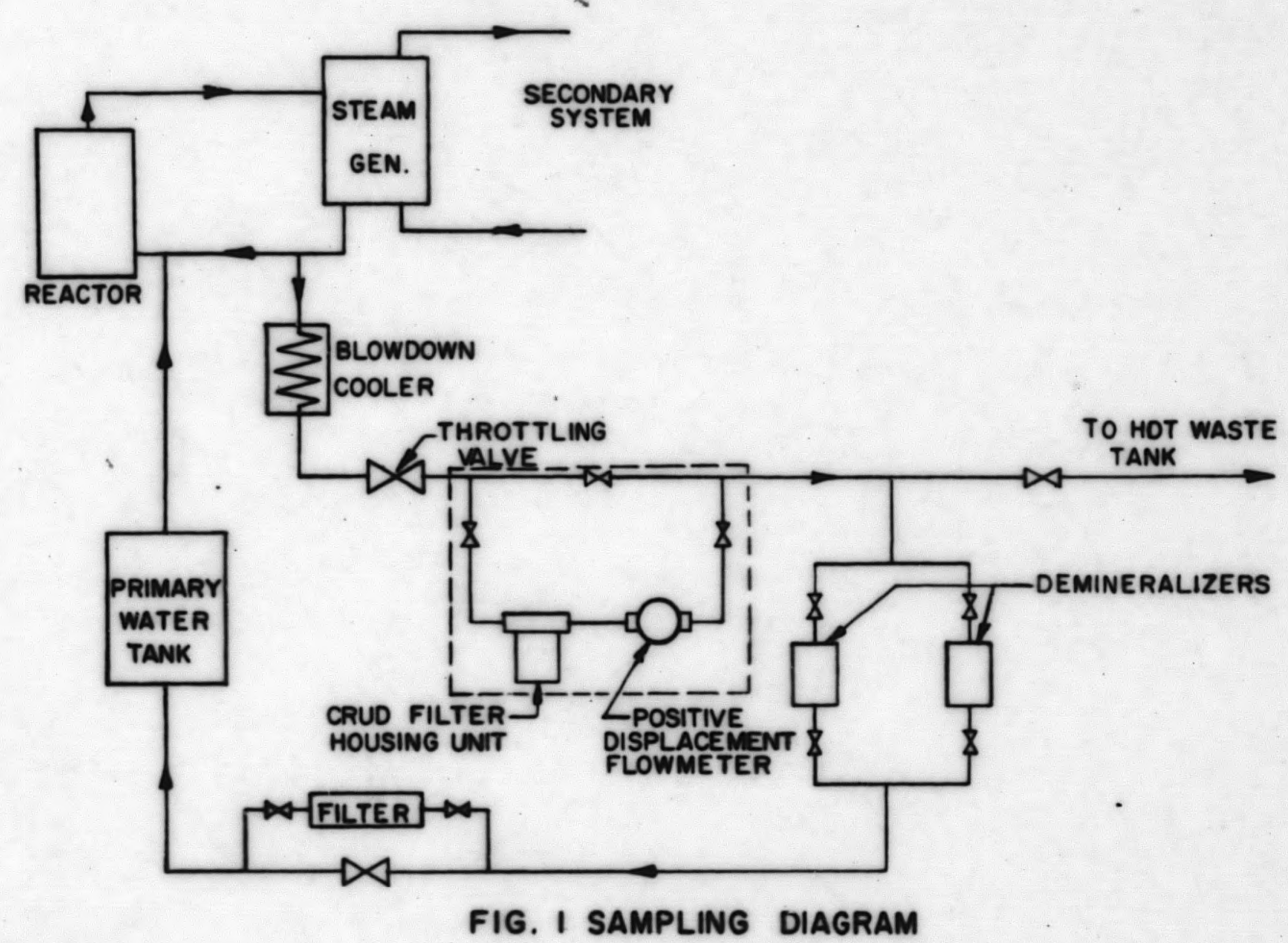


made to remove all crud and activity from the filter elements by means bf a chemieal decontaminating solution. The decontaminhting solutions used actually removed about 80 percent of the activity from the filter. The solution was then evaporated to dryness, ignited to remove volatile and organic matfter, and the oxide residue dissolved and radiochemically analyzed. It was expected that the weight of the oxide residue would be an accurate measure of the total weight of crud collected. This general procedure was used on the first nine filters. However, since it was found that this technique did not permit a direct determination of the weight of crud collected, an alternate procedure was used for samples 10-12. For these samples, the crud was removed directly from the filter by backwashing, weighed, and brought into solution for analysis. A limitation of this procedure was that only about $25 \mathrm{p}$ cent of the activity was removed by backwashing.

The detailed procedures followed for removal and dissolution of the crud are as follows:

\section{EDTA-Sulfamic Acid Method (Samples 1 - 5).}

The filter element was placed in a solution containing 13 grams EDTA (ethylenediaminetetraacetic acid disodium salt) and $\mathbf{1 2}$ grams of sulfamic acid in $600 \mathrm{ml}$. of distilled water at $150-160^{\circ} \mathrm{F}$ for one hour. The filter was removed from the decontaminating solution, and the graphite and insoluble material filtered off and ignited over a Meeker burner. The filtrate was treated with $25 \mathrm{ml}$. each of concentrated nitric acid and concentrated sulfuric acid and evaporfted to dryness. The residue was combined with the ignited oxides, and mixed with 20 parts by waight of a fusion mixture $\left(50-50 \mathrm{Na}_{2} \mathrm{CO}_{3}-\mathrm{K}_{2} \mathrm{CO}_{3}\right)$. The 
mixture was fused at $1300-1400^{\circ} \mathrm{F}$ for one hour, cooled, and dissolved slowly in 3 Nhydrochloric acid. An acid insoluble salt residue was removed by centrifugation and discarded, since it contained no measurable radioactivity. The supernate was then made up to a definite volume for analysis.

\section{EDTA-Oxalic Acid Mixture (Samples 6,7)}

The decontaminating solution was essentially the same as the above, except oxalic acid was substituted for sulfamie acid. This solution and the insoluble material removed from the filter was treated successively with sulfuric, nitric, and perchloric acids. After evaporating to fumes of perchloric acid to destroy organic matter, the solution was centrifuged to remove insoluble material. The insoluble material was fused as above, and dissolved in $\mathbf{3} \mathbf{N C L}$. As with samples 1-5, there was an acid insoluble, non-radioactive residue which was discarded. The two solutions were combined and made up to volume for analysis.

3. EDTA-Citric Acid Method (Samples 8, 9)

The unit was decontaminated in a solution consisting of equal weights of EDTA and citric acid (1 gram) in $600 \mathrm{ml}$. of distilled water at $160^{\circ}-180^{\circ} \mathrm{F}$ for 1- 2 hours. The solution was then treated in the same manner as the EDTA-oxalic acid method.

\section{Filter Backflushing Method}

The filter unit was backflushed with air and water to remove as much activity as possible. A rubber policeman was used to remove any loosely adherent material. The water and crud solution was then evaporated to dryness in a tared platinum dish, ignited, and weighed to determine the amount of insoluble material recovered. This residue was then successively treated with a mixture of nitric, perchloric, and hydrofluoric acids until dissolution was attained. The 
solution was then made up to a known volume for analysis.

\section{DETERMANATION OF CRUD WEIGHTS}

The crud removal and dissolution procedures followed for samples 1 - 9 did not permit a direct determination of the weight of insoluble material (crud) removed from the filter. This became evident when analyzing aliquots of the final solutions. Metal hydroxides which were precipitated from an aliquot by sodium hydroxide, washed, and ignited, yielded oxide weights considerably higher than would be normally expected. Crud weights for samples 1 - 9 were therefore calculated indirectly from chemical analysis of the dissolved crud solutions. These calculated weights of crud are given in Table I. Crud weights for samples 10, 11, 12 were measured directly by weighing the insoluble material recovered by backflushing the filter element. These weights are also included in Table $\mathbf{I}$.

Chemical anatyseswere made by standard colorimetric methods using a Beckman DU spectrophotometer. Aliquots of the solutions were analyzed for iron, nickel, chromium, manganese, and cobalt. It was assumed that the oxides of these elements accounted for 100 percent of the weight removed from the filter. Results of the chemical analyses are reported in Table II. The variation in results indicates that the decontaminating solutions had a definite effect on the calculated weight of crud. Also, each of the three chemical solutions apparentiy attacked the stainless steel of the filter element in a different manner. 
TABLE I

SAMPLE CRUD WEIGHTS

Sample No.

1

2

3

4

5

6

7

8

9

10

11

12
Crud Filter Decontaminating Solution

EDTA + Sulfamic Acid

EDTA + Sulfamic Acid

EDTA + Sulfamic Acid

EDTA + Sulfamic Acid

EDTA + Sulfamic Acid

EDTA + Oxalic Acid

EDTA + Oxalic Acid

EDTA + Citric Acid

Filter Backwashed

Filter Backwashed

Filter Backwashed
170

298

52

40

Crud Weight *

mg.

174

89

79

398

123

$50 * *$

24

64

* Calculated as the total metal oxides: $\mathrm{Fe}_{3} \mathrm{O}_{4}, \mathrm{NlO}_{2} \mathrm{MnO}_{2}, \mathrm{Cr}_{2} \mathrm{O}_{3}$. **Direct weight of recovered material. 


\section{TABLE II}

\section{CHEMICAL COMPOSETION OF CRUD}

EXPRESSED AS PERCENT OF TOTAL METAL

\begin{tabular}{cc}
$\begin{array}{c}\text { Sample } \\
\text { No. }\end{array}$ & $\begin{array}{c}\text { Chemical Decontamination } \\
\text { Solution }\end{array}$ \\
1 & EDTA + Sulfamic Acid \\
2 & EDTA + Sulfamic Acid \\
3 & EDTA + Sulfamic Acid \\
4 & EDTA + Sulfamic Acid \\
5 & EDTA + Sulfamic Acid \\
6 & EDTA + Oxalic Acid \\
7 & EDTA + Oxalic Acid \\
\hline 8 & EDTA + Citric Acid \\
\hline & EDTA + Citric Acid
\end{tabular}

$\begin{array}{ccccc}\% & \% & \% & \% & \% \\ \text { Fe } & \text { Ni } & \text { Cr } & \text { Mn } & \text { Co }\end{array}$

$\begin{array}{lllll}64.0 & 18.0 & 3.3 & 14.7 & 0\end{array}$

$\begin{array}{lllll}79.0 & 4.9 & 4.35 & 13.0 & 0\end{array}$

$\begin{array}{lllll}71.5 & 13.6 & 3.6 & 11.2 & 0\end{array}$

$\begin{array}{lllll}69.1 & 15.7 & 0.6 & 14.7 & 0\end{array}$

$\begin{array}{lllll}86.0 & 8.7 & 5.8 & 0 & 0\end{array}$

$\begin{array}{lllll}48.5 & 53.0 & 0 & 0 & 0\end{array}$

$\begin{array}{lllll}68.5 & 31.0 & 0 & 0,6 & 0\end{array}$

$\begin{array}{lllll}88.0 & 12.0 & 0 & 0 & 0\end{array}$

$\begin{array}{lllll}96.0 & 4.0 & 0 & 0 & 0\end{array}$ 


\section{RADIOCHEMICAL PROCEDURES}

The activity of the dissolved crud solutions was sufficiently high so that it was not necessary to perform a general chemical separation of the elements. Instead small aliquots of the solution were analyzed directly for cobalt, iron, manganese, and chromium according to the procedures outlined in the Appendix. Analyses were corrected for the amount of iron present in the crud. Corrections for the other elements were not required, since the aliquots contained only negligible amounts of those metals.

Samples were counted for $\mathrm{Co}^{60}, \mathrm{Co}^{58}, \mathrm{Fe}^{59}, \mathrm{Mn}^{54}$, and $\mathrm{Cr}^{51}$ by a modified method of Connalley and Leboeuf $(1,3)$ using the photopeak height $\mathbf{r}_{\max }$ and the width of the photopeak at $1 / 2 \mathbf{r}_{\max }$. The counts were corrected for decay back to the midpoint of the sample collection period. $\mathrm{Fe}^{55}$ could not be counted by this technique. In our previous measurements (1), $\mathrm{Fe}^{55}$ had been reported to have a total disintegration energy of $0.21 \mathrm{Mev}$. This energy is actually emitted in a continuous spectrum. A check of this energy peak indicated a decay with a half life closely approximating that of $\mathrm{Fe}^{59}$ (45 days). It therefore could only be concluded that the peak in question was in reality due to Compton scattering from $\mathrm{Fe}^{59}$. Work is still continuing to $\mathrm{fi}$ nd a suitable quantitative method for detecting $\mathrm{Fe}^{55}$. The manganese $\mathrm{K}$-Xray emitted as a result of the electron capture of $\mathrm{Fe}^{55}$ cannot be observed with the present equipment.

It is possible that the presence of $\mathrm{Co}^{58}$ can lead to an error when measuring $\mathrm{Co}^{60}$ at the $1.33 \mathrm{Mev}$ peak with the gamma spectrometer. On a theoretical basis, the $0.51 \mathrm{Mev}$ position annihilation radiation and the $0.81 \mathrm{Mev}$ gamma ray from $\mathrm{Co}^{58}$ may combine to give $1.32 \mathrm{Mev}$ gamma energy. Therefore, 
the possibility exists that the counts measured at the $1.33 \mathrm{Mev} \mathrm{Co}^{60}$ peak may partially be due to radiation "scattering up" from $\mathrm{Co}^{56}$. Since the present method of analyses for $\mathrm{Co}^{60}$ consists of measuring the photopeak heights at 1.17 and 1.33 Mev, the results reported from the $1.33 \mathrm{Mev}$ peak could be in error. The effect of this phenonemena on our results is discussed in Section V A.

\section{DISCUSSION OF RESULTS}

During the period covered by this report, the APPR-1 was operating on a schedule of twenty days at continuous power level followed by approximately nine days at intermittent low power and shutdowns for training purposes. The effects of this erratic type of operation must be considered when analyzing the data. Figure 2 is a plot of the APPR-1 ${ }^{\circ}$ F days* as a function of time. The slope of the line is a direct indication of the power level. The reduced slopes (dotted lines) represent periods of shutdown and operation at low power levels. Since steady state conditions are not reached under these conditions, nuclide activation becomes complex. The nuclides $\mathrm{Fe}^{59}$ and $\mathrm{Cr}^{51}$ will decay more rapidly, leaving the bulk of the activity asigociated with the long lived nuclides $\mathrm{Mn}^{54}$ and $\mathrm{Co}^{60}$.

\section{A. SPECIFIC ACTIVITY OF CRUD AS A FUNCTION OF EQUIVALENT FULL POWER HOURS}

The variation in the nuclide specific activities with increasing reactor operating time is summarized in Table III. For the first nine samples, the actual specific activities of the nuclides may be different than the results reported in this table. The possiblity of error arises from two sources:

$* 1^{\circ} \mathrm{F}$ day $=1.2$ equivalent full power hours

$=0.00137$ MWYR 
1. The acid-complexing agent used to decontaminate the crud filter may actually have removed activity associated with colloidal and soluble material, in addition to the activity associated with the insoluble crud. It has been reported ${ }^{(4)}$ that porous stainless steel filters will retain activity associated with colloidal and soluble material.

2. The calculated weights of crud, from which the specific activity is found, may be high due to attack on the steel filter by the chemical decontaminating solutions. It is suspected from the chemical analysis results, that some attack did in fact occur, particularly with Samples 1-7.

The specific activity results of Samples 10, 11, and 12 can be considered the most reliable, since the activity was removed by backflushing with water. These values can be assigned with confidence to insoluble material which is. large enough to be retalned by the stainless steel filter ( 2 microns or greater). However, it should be pointed out that all of the insoluble material may not have been removed by the backwashing procedure. If the activity associated with insoluble corrosion products is independent of particle size, the specific activity values are not affected. The specific activity of crud probably is independent of particle size (5). Caution must be exercised in comparing the results of Samples 10-12 with Samples 1-9 because of the difference in treatment of the collected crud. Examination of the data of Table III reveals the specific activities of cobalt on a volume basis do not change appreciably throughout the interval covered in this study except in the case of Sample 12. However, the cobalt results expressed on a weight basis $(\mathrm{dpm} / \mathrm{mg})$ show larger variations. The overall trend appears to be an increase in the weight specific activity with reactor operating time, with the volume specific activity remaining relatively constant. 


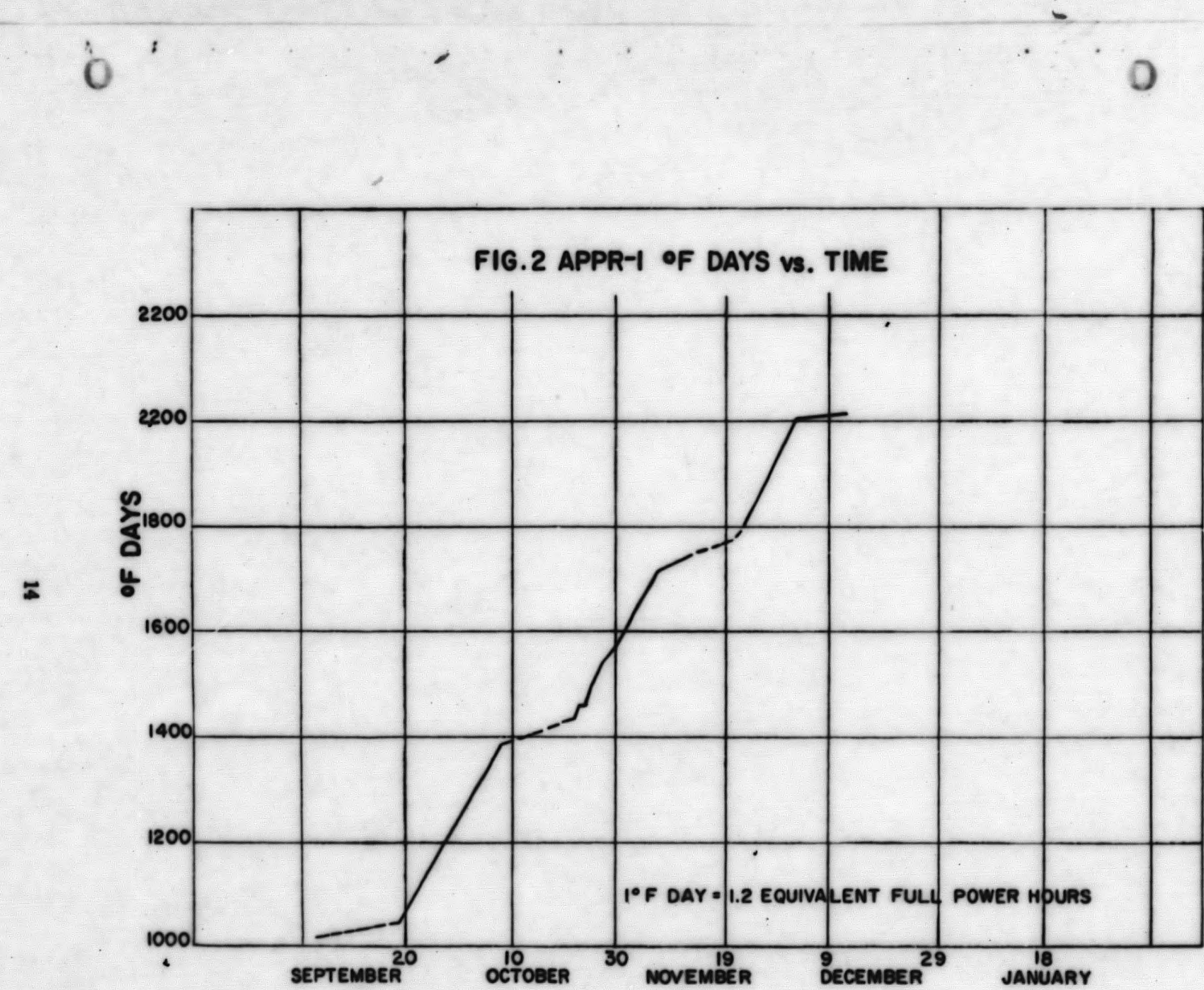




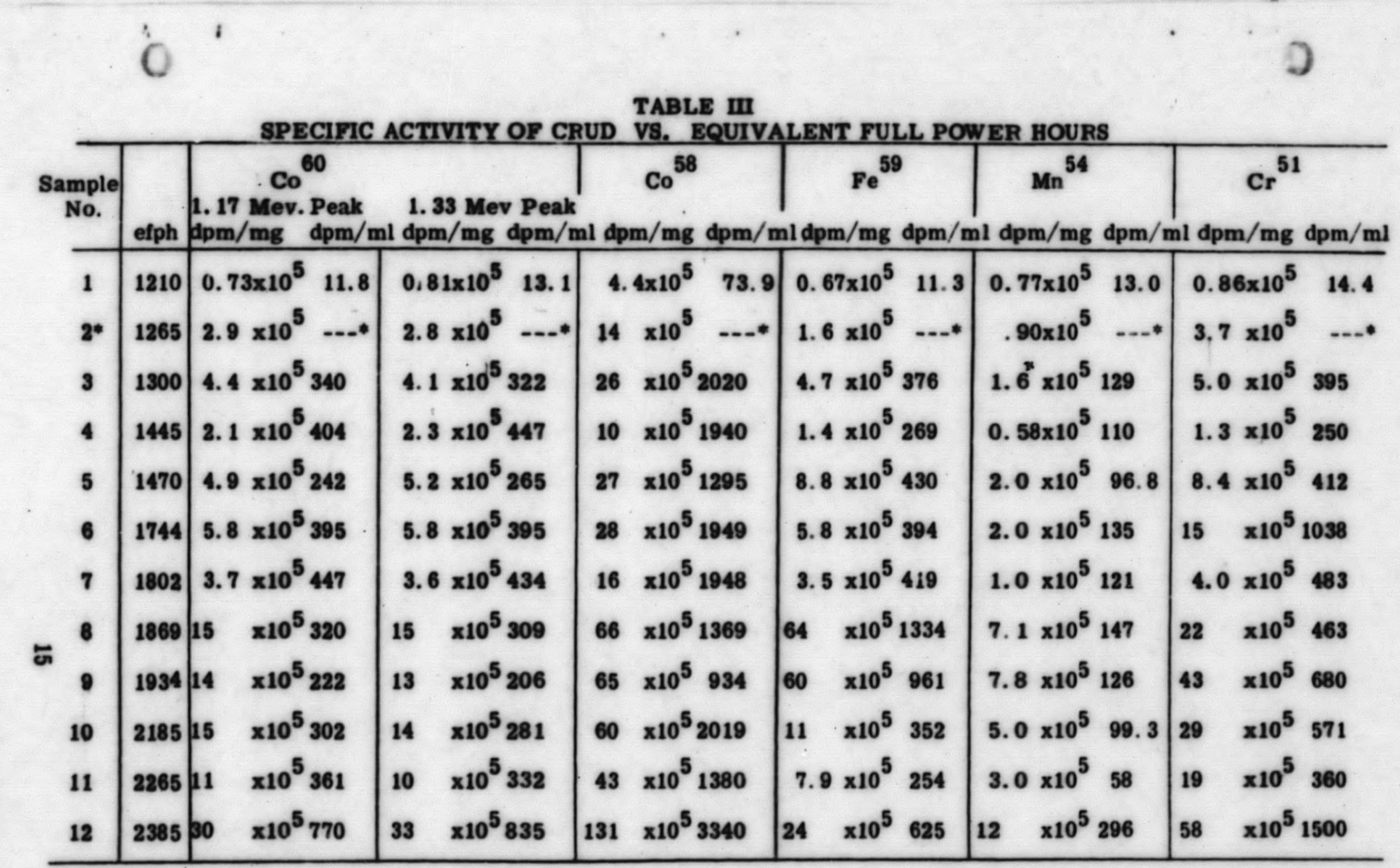

- No Flow Data 
Since the volume specific activity $(\mathrm{dpm} / \mathrm{ml})$ is dependent on crud level, a relationship may possibly exist between the crud level and weight specific activity. More data is required to establish if a definite relationship does exist.

The large increase in the specific activity on both the volume and weight basis observed in Sample 12 is difficult to explain. The difference is real since the duplicate samples agreed well. The time at power between Sample 11 and 12 is not long enough to account for this large variation. Since both volume and weight values increased the deviation from expected behavior is perhaps attributable to a non-representative sample.

Samples 8 and 9 , in which citric acid - EDTA was the complexing agent, show a considerably higher weight specific activity than the previous samples. This could possibly be attributed to the greater complexing ability or the less corrosive attack of this solution on the structural material of the filter element. Probably both mechanisms are simultaneously involved resulting in the large increase. The volume specific activities of these two samples are comparable to those for other samples, except in the case of $\mathrm{Fe}^{59}$. This might indicate that the citric acid-EDTA-iron complex is stronger than the other metal ion complexes, so that the iron activity is preferentially removed. From this data in Table III, the effect of $\mathrm{Co}^{58}$ scattering on the $\mathrm{Co}^{60}$ results can be obtained. If this additive scattering were a significant factor, it would be expected that the results from the $1.33 \mathrm{Mev}$ peak of $\mathrm{Co}^{60}$ would be consistently higher than the results from the $1.17 \mathrm{Mev}$ peak of $\mathrm{Co}^{60}$. An examination of the data from the two $\mathrm{C}^{2}$ peaks shows a maximum difference between two values of about 10 percent, with the average variation about five percent. In approximately half of the cases where there is a differenece, the 1.17 peak is 
in fact higher than the 1.33 peak. On the hasis of these observations the differences observed are attributed to experimental error. Further observations on the possiblity of this additive scattering will be made by measuring the decay rate of the samples at the 1.33 Mev peak.

The cobalt, iron, manganese, and chrosifium nuclides accounted for all of the long-lived gamma activity in the samples. In several cases the material balance on the separated fractions apparently accounted for more than $100 \%$. The paradox is explained by the very high counting rates of the gross samples using our method of assay ${ }^{(1)}$. The counting rates are sufficiently high to have appreciable coincidence loss, even when employing scintillation counting techniques.

\section{B. NUCLIDE RATIO'DATA}

Table IV presents the ratios of the specific activity of each nuclide to the specific activity of $\mathrm{Co}^{60}$. The ratios were calculated to $\mathrm{Co}^{60}$ since this nuclide is of principal interest in activity build-up problems because of its nuclear properties -- long half-life and two cascading hard gammas per disintegration. The use of ratios eliminates some of the errors previously mentioned that could be present in the absolute values of the specific activity. For example, If the specific activity is in error primarily due to material being dissolved from the filter, this error will be canceled in the ratio. In addition, in the case of $\mathrm{Co}^{58} / \mathrm{Co}^{60}$ ratios, chemical errors will also be eliminated. The ratios of $\mathrm{Co}^{58} / \mathrm{Co}^{60}$ and $\mathrm{Mn}^{54} / \mathrm{Co}^{-60}$ are plotted as a function of equivalent full power hours in Figure 3 and Figure 4 respectively. The curves were determined by the method of least squares. The decreasing $\mathrm{Co}^{58} / \mathrm{Co}^{60}$ ratio indicates that the specific activity of $\mathrm{Co}^{60}$ is accumulating at a faster rate 
than that of $\mathrm{Co}^{58}$. It is still too early to predict what the equilibrium value for this ratio will be, or whether the $\mathrm{Co}^{60}$ specifto activity will eventually overtaike the $\mathrm{Co}^{58}$ specific activity. Figure 4 indicates that $\mathrm{Mn}^{54}$ specific activity is accumulating at about the same rate as that of $\mathrm{Co}^{60}$.

It is thiteresting to note that the value of the $\mathrm{Co}^{58} / \mathrm{Co}^{60}$ ratios for these crud samples is nearly the same as the $\mathrm{Co}^{58} / \mathrm{Co}^{60}$ ratio for the total activity measured in the water samples at the end of the 700-hour test. On sample 711, the last water sample of the 700 -hour test, the $\mathrm{Co}^{58} / \mathrm{Co}^{60}$ was

4.5. The fact that the values in Table III were calculated from the weight specific activities, while the 700-hour water sample ratios were from volume specific activities is of no consequence. The ratios are the same whether volume or weight specific activities are used. 
TABLE IV. NUCLIDE RATIO DATA

\begin{tabular}{|c|c|c|c|c|}
\hline Sample & $\mathrm{Co}^{58} / \mathrm{Co}^{60}$ & $\mathrm{Fe}^{59} / \mathrm{Co}^{60}$ & $\mathrm{Mn}^{54} / \mathrm{Co}^{60}$ & $\mathrm{Cr}^{51} / \mathrm{Co}^{60}$ \\
\hline 1 & 5.7 & 0.9 & 1.0 & 1.1 \\
\hline 2 & 5.1 & 0.6 & 0.3 & 1.3 \\
\hline 3 & 6.1 & 1.1 & 0.4 & 1.2 \\
\hline 4 & 4.6 & 0.6 & 0.4 & 0.6 \\
\hline 5 & 5.2 & 1.7 & 0.4 & 1.7 \\
\hline 6 & 4.9 & 1.0 & 0.3 & 1.1 \\
\hline 7 & 4.5 & 1.0 & 0.3 & 1.1 \\
\hline 8 & 4.3 & 4.2 & 0.5 & 1.5 \\
\hline 9 & 4.9 & 4.5 & 0.6 & 3.2 \\
\hline 10 & 4.2 & 0.7 & 0.3 & 2.0 \\
\hline 11 & 4.0 & 0.8 & 0.3 & 1.7 \\
\hline 12 & 4.2 & 0.8 & 0.4 & 1.9 \\
\hline
\end{tabular}




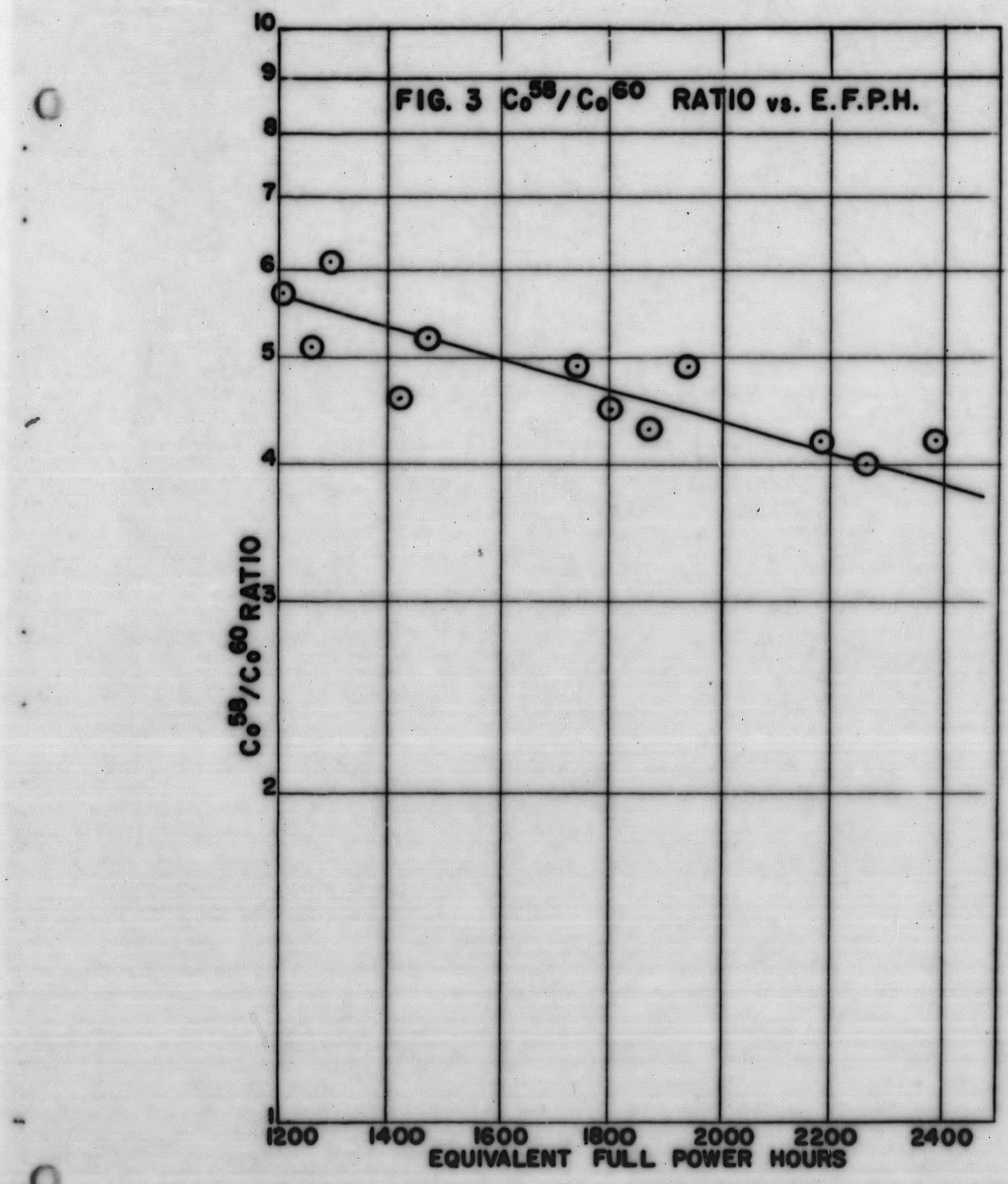




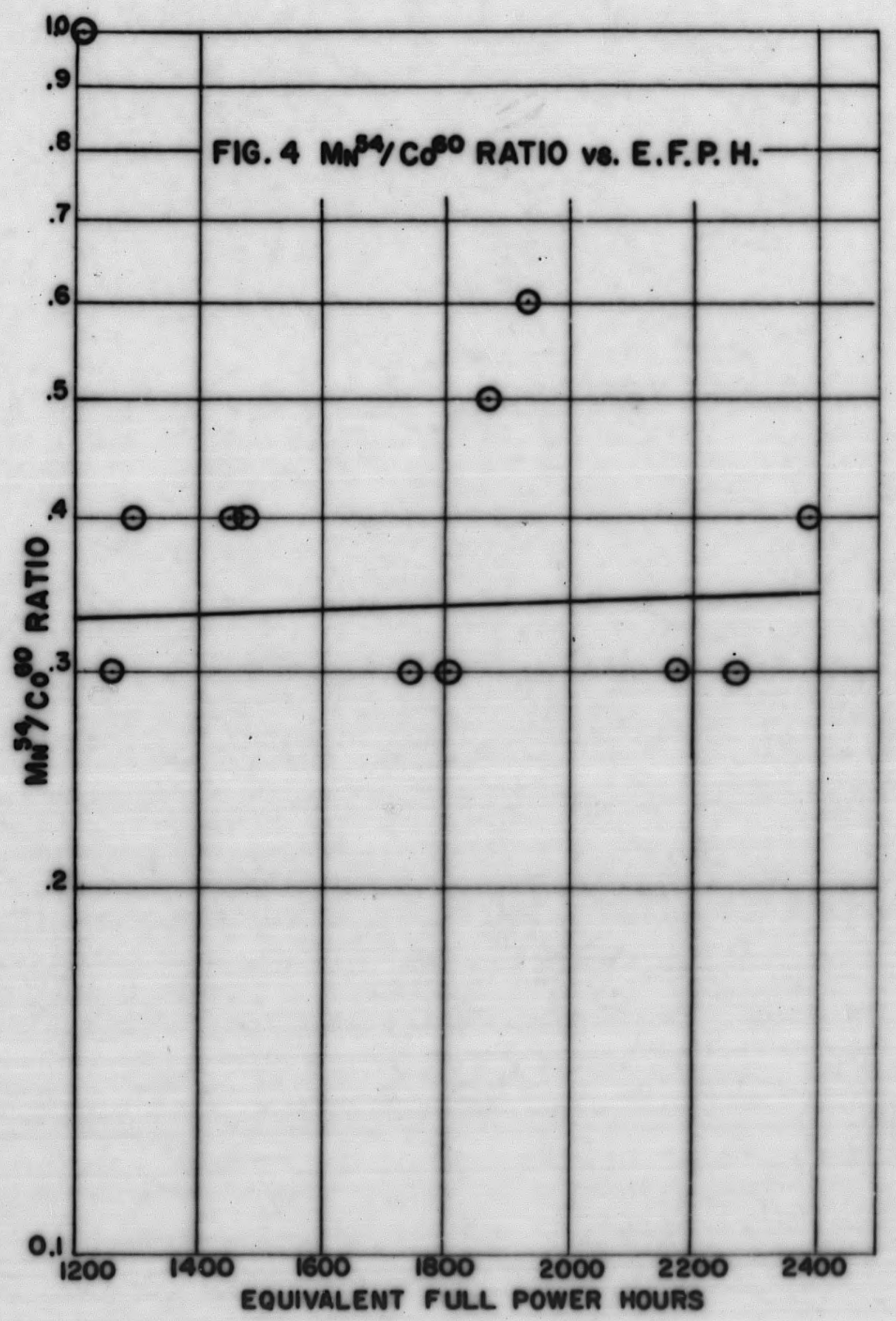




\section{CRUD LEVEL AND SPECIFIC ACTIVITY}

The term "crud level" has been used in the literature in several different ways. The definition depends upon such factors as the method of sampling or collecting the crud, and the metbods followed to recover and calculate the amount of crud collected. Consequently, it ts necessary to define the term as it appears in this report. Crud levels for Samples 1-9 were determined on the calculated weight of material, as determined by chemical analysis, removed from the porous steel filter by the decontaminating solutions. The results are expressed on the basis of the total flow through the filter unit, 1.e., milligrams of crud per liter of flow (ppm). Crud levels for samples 10-12 were determined from the amount of material removed by backflushing the filter with air and distilled water unitl no further activity was removed. Levels were expressed in the same manner as Samples 1-9. Crud levels for these samples would be expected to be lower than for the first nine samples, but the values of specific activity for these-samples are more reliable.

The specific activity and the çrud level are two of the factors that can affect the activity buildup. The values for these parameters measured during this study are given in Table V. The results for the first nine samples may be in error for the reasons previously mentioned.

\section{WAPD has investigated ${ }^{(6)}$ whether there is a relationship between} crud specific activity and crud level. In view of the uncertainties in our results, we do not feel justified in drawing a conclusion from this data as to whether a relationship exists between the specifie activity and crud level. However, because of the importance of these parameters, further data on their values should be obtainep. 
TABLE V

CRUD LEVEL VS CRUD SPECIFIC ACTIVITY

\section{Sample}

1

2

3

4

5

6

7

8

9

10

11

12
Total

Specific Activity

(dpm/mg) x10 15

7.49

41.4

15.6

50.6

56.2

28.5

174.

189.

120.

83.5

256.
Crud Level

(ppm)

0.17

1.9

0.78

0.49

0.69

1.2

0.21

0.16

0.20

0.10

0.29 


\section{DEPOSITED VS CIRCULATING ACTIVITY}

Investigations at WAPD (7) have indicated that the specific activity of loosely bound deposited material is probably of the same order of magnitude as the specific activity of eirculating crud. However, little data is available on whether adherent deposits follew this relationship. During this study, one piece of datum was collected on the relationship between deposited activity and circulating activity. The results reported below are basef upon one measurement only, and this should be borne in mind when interpreting the data.

At the end of the 700-hour test, a section of the baffle plate was. removed from the steam generator and sent to Schenectady for radiochemical studies. In the process of obtaining and shipping the sample, any loosely bound material would have been lost. Therefore the relationships discussed below are only applicable to tightly bourd material. The baffle plate was decontaminated with the EDTA-sulfamic acid solution previously described. Table VI presents the nuclide ratio data from this sample and compares it to the nuclide ratios Irom the last water sample (No. 711) of the 700-hour test. Both samples had a similar reactor history.

The difference between the $\mathrm{Co}^{58} / \mathrm{Co}^{60}$ ratios in the two samples is larger than can be explainad by experimental error. If the deposited activity arises from a strictly chemical phenomena, the $\mathrm{Co}^{58} / \mathrm{Co}^{60}$ ratio would be expected to be the same, since the two cobalt nuclides would behave chemically identical. If a physical phenomena, such as diffusion, plays a part in the accumulation of deposited activity, the difference in the mass of the nuclides would become a factor. 
TABLE VI

NUCLIDE RATIOS OF DEPOSITED AND CIRCULATING ACTIVITY

Sample

Baffle Plate

711

$$
\mathrm{Co}^{58} / \mathrm{Co}^{60}
$$

6.0

4.5
$\mathrm{Fe}^{59} / \mathrm{Co}^{60}$

0.08

0.26

.20

0.28

0.39

One mechanism which could explain these observations could be an initial ratedetermining E.M.F. reaction followed by a rapid homogeneous exchange reaction between the active and inactive nuclides. Figure 5 is a diagramatic outline of this mechanism.

FIG. 5

POSSIBLE MECHANISM FOR ACCUMULATION OF ACTIVITY IN DEPOSITS

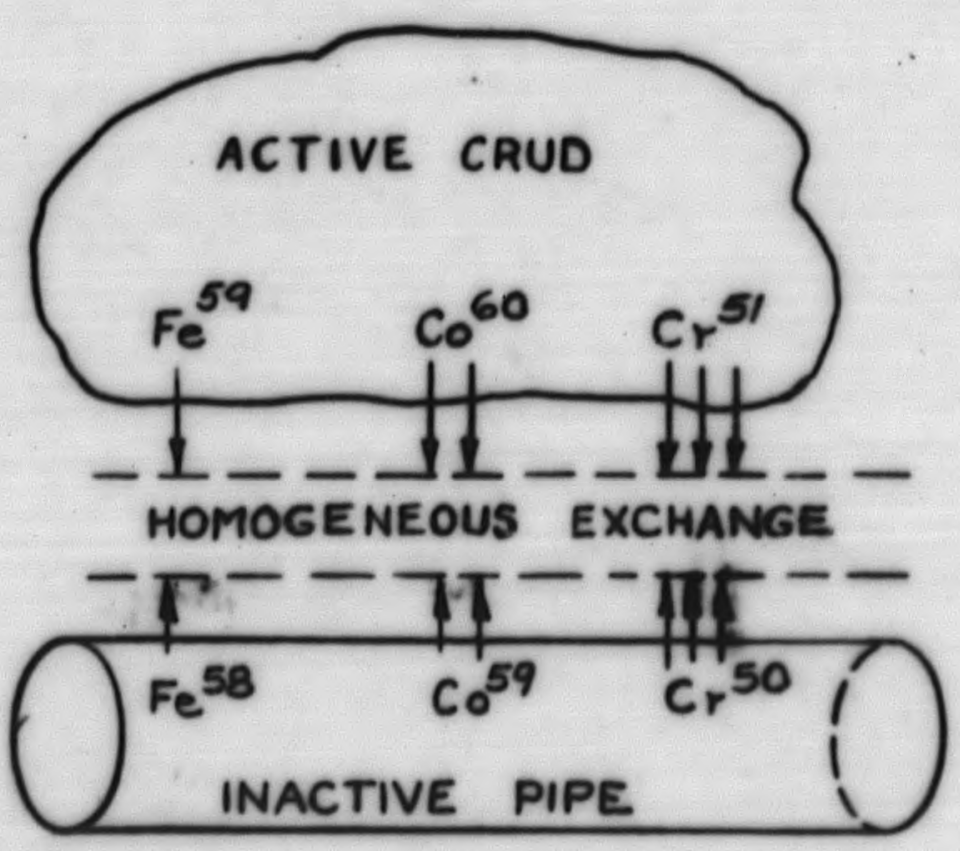


It will be assumed the majority of the radioactive iron, cobalt, and chromium is associated with insoluble material. These elements (both active and inactive species) would enter into solution relative to their E.M.F. potentials $\left(M^{0} \rightarrow M^{n^{+}}+n e\right)$. Since iron to more noble than cobalt and cobalt more noble than chromium, the rates with which these elements would enter solution would be in the order chromium $>$ cobalt $>$ iron. Once in solution there would be rapid exchange between the active and Inactive nuclides. A "plating out" could then occur with the exchanged nuclides. The rates of this reaction would be in reverse order to the dissolution step, i.e. Iron $>$ cobalt $>$ chromium. With thif mechanism, an analysis shows the rate of accumulation of chromium in the deposit is faster than cobalt, which in turn would be faster than iron.

Additional work is required to accurately establish the relationship between deposited and circulating activity, and to define the mechanism by which activity builds up on the metal surfaces of the primary system components. 


\section{APPENDIX}

\section{DECONTAMINATION SCHEME}

FOR CRUD SAMPLES

\section{IRON}

$2 \mathrm{ml}$ Crud solution

$2 \mathrm{ml} \mathrm{Standard} \mathrm{Fe}^{+++}$carrier $(10 \mathrm{mgs} / \mathrm{cc}$ )

$2 \mathrm{ml} \mathrm{Non-Standard} \mathrm{Co}^{++}$carrier

Add 1:2 $\mathrm{NH}_{4} \mathrm{OH}$

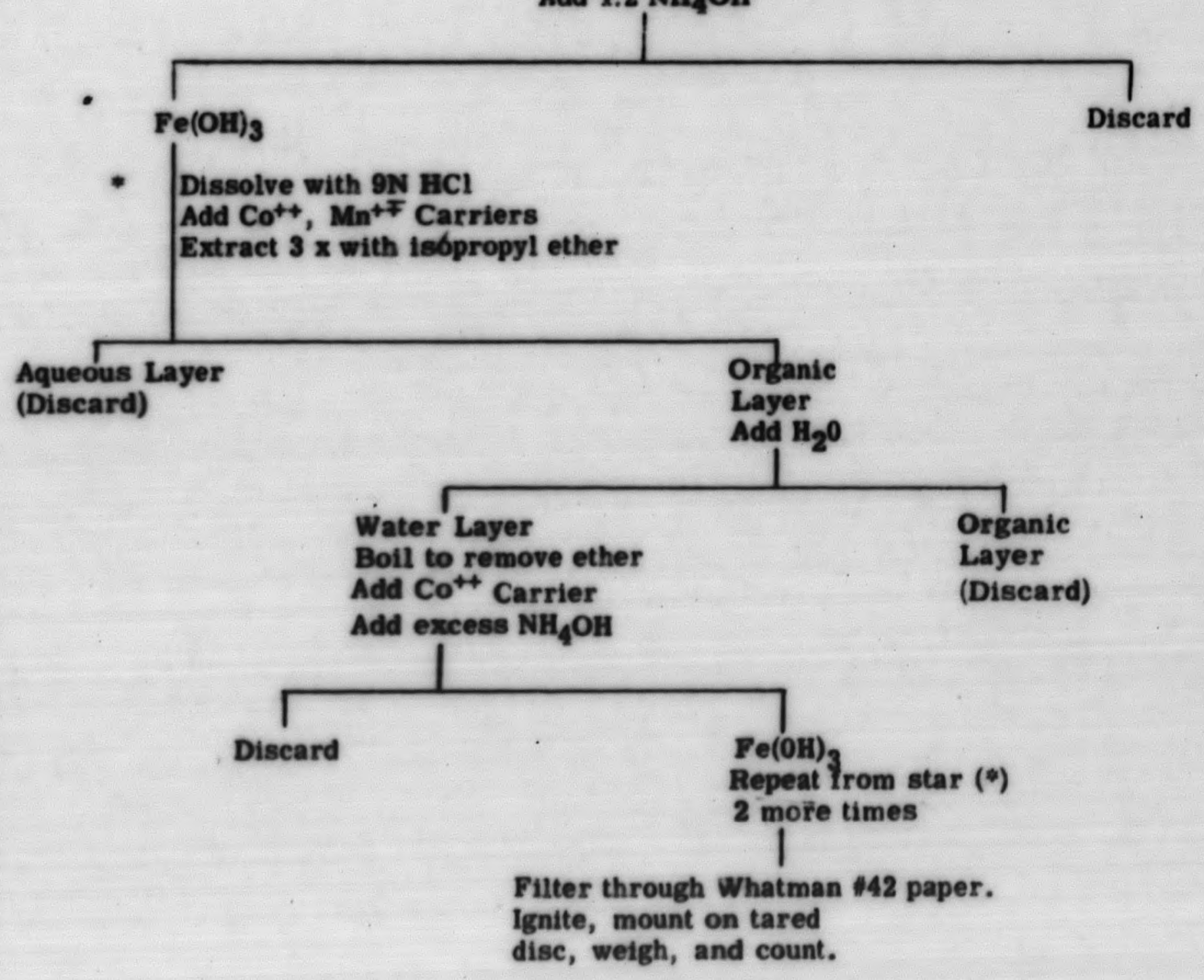




\section{COBALT}

$2 \mathrm{ml}$ Crud solution

$2 \mathrm{ml} \mathrm{Standard} \mathrm{Co}^{++}$carrier $(10 \mathrm{mgs} / \mathrm{ml}$ )

Add $6 \mathrm{~N} \mathrm{NaOH}$ Discard $T$ Co(OH)

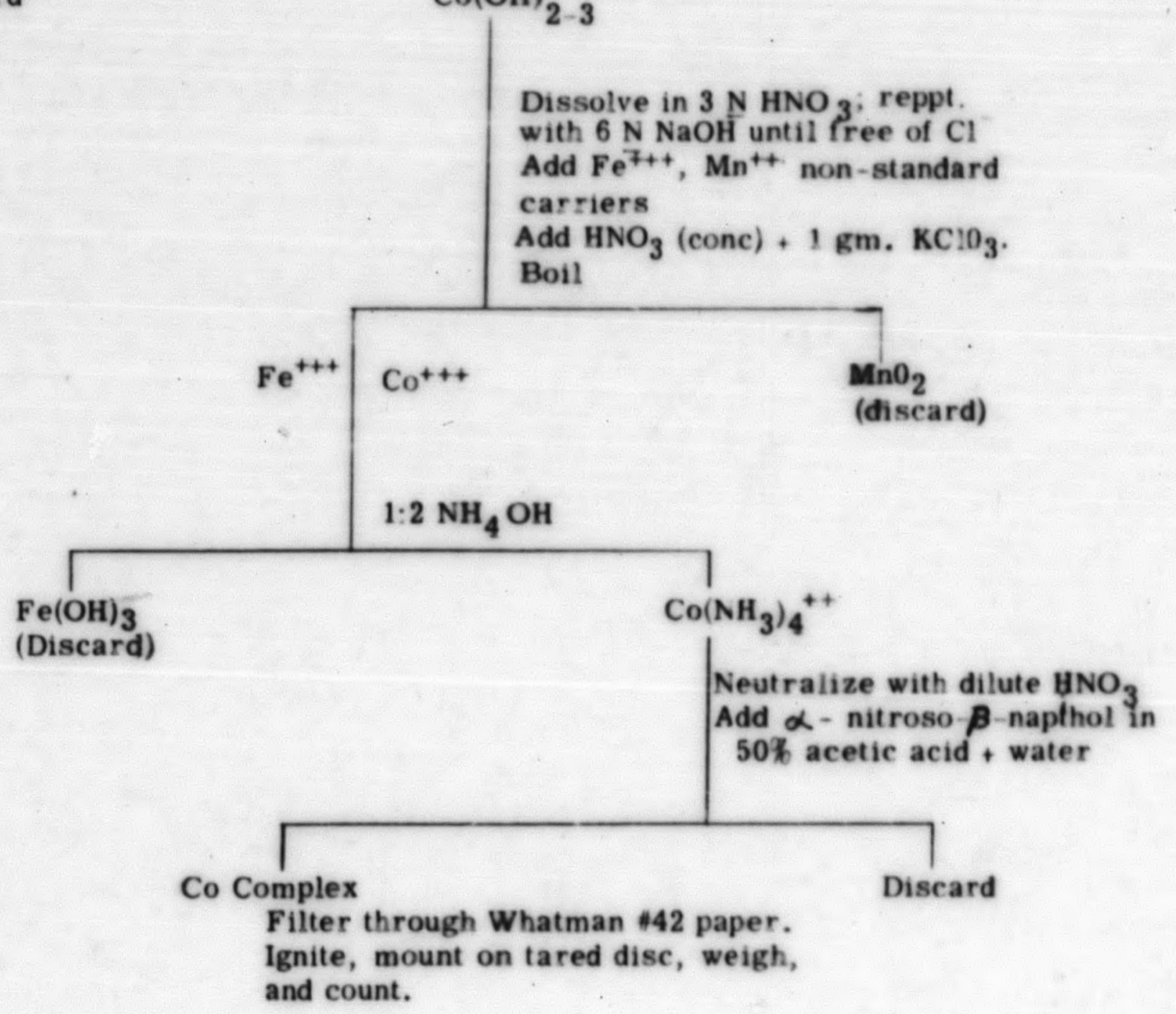




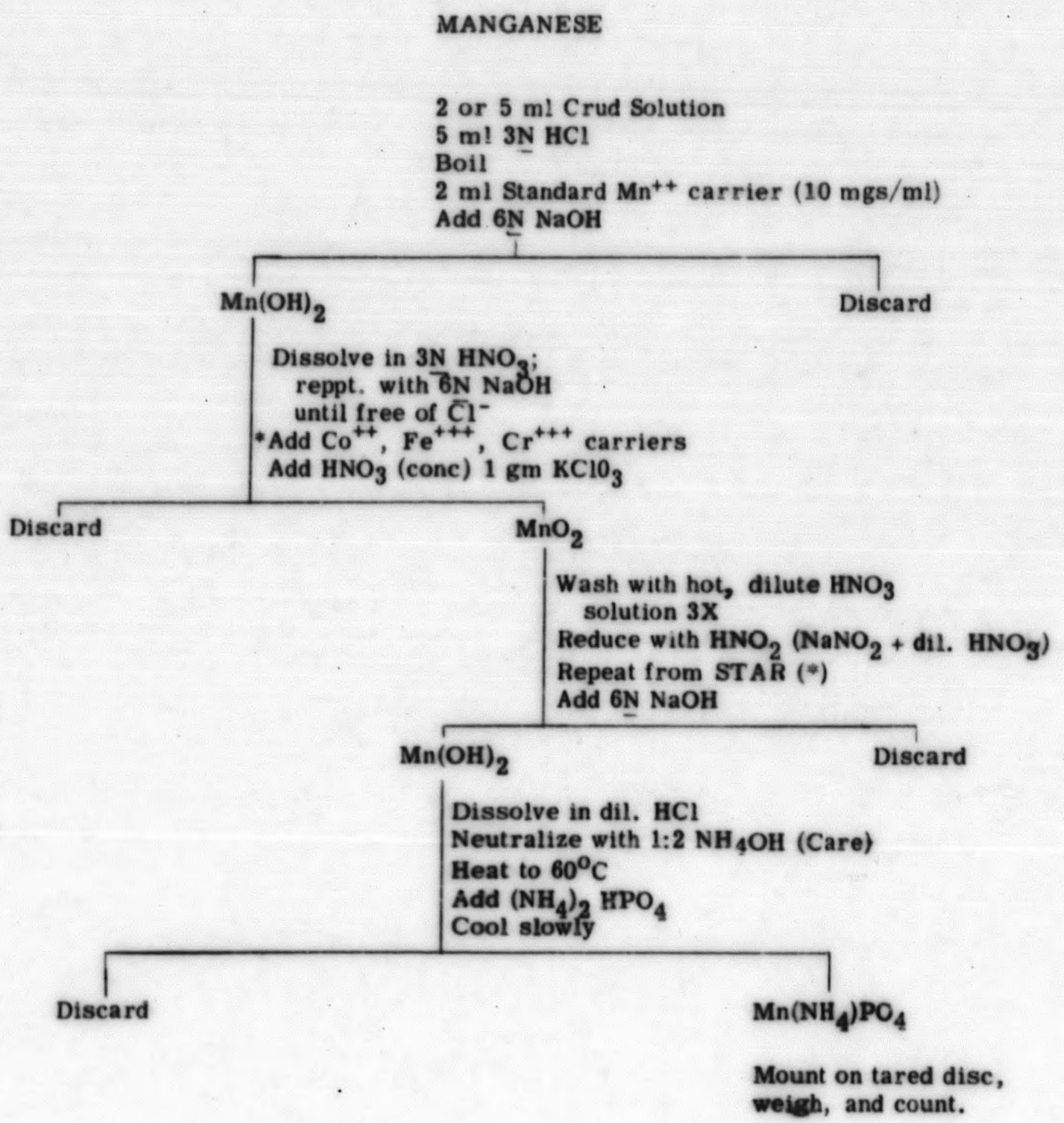




\section{CHROMIUM}

2 or $5 \mathrm{ml}$ Crud solution

$2 \mathrm{ml}$ Standard $\mathrm{Cr}^{+++}$carrier $(10 \mathrm{mgs} / \mathrm{ml})$

(1) Make basic and add $\mathrm{H}_{2} \mathrm{O}_{2}$

(2) Make acid and add $\mathrm{H}_{2} \mathrm{O}_{2}$

Heat to $60^{\circ} \mathrm{C}$

Add sat'd solution $\mathrm{Ba}\left(\mathrm{NO}_{3}\right)_{2}$

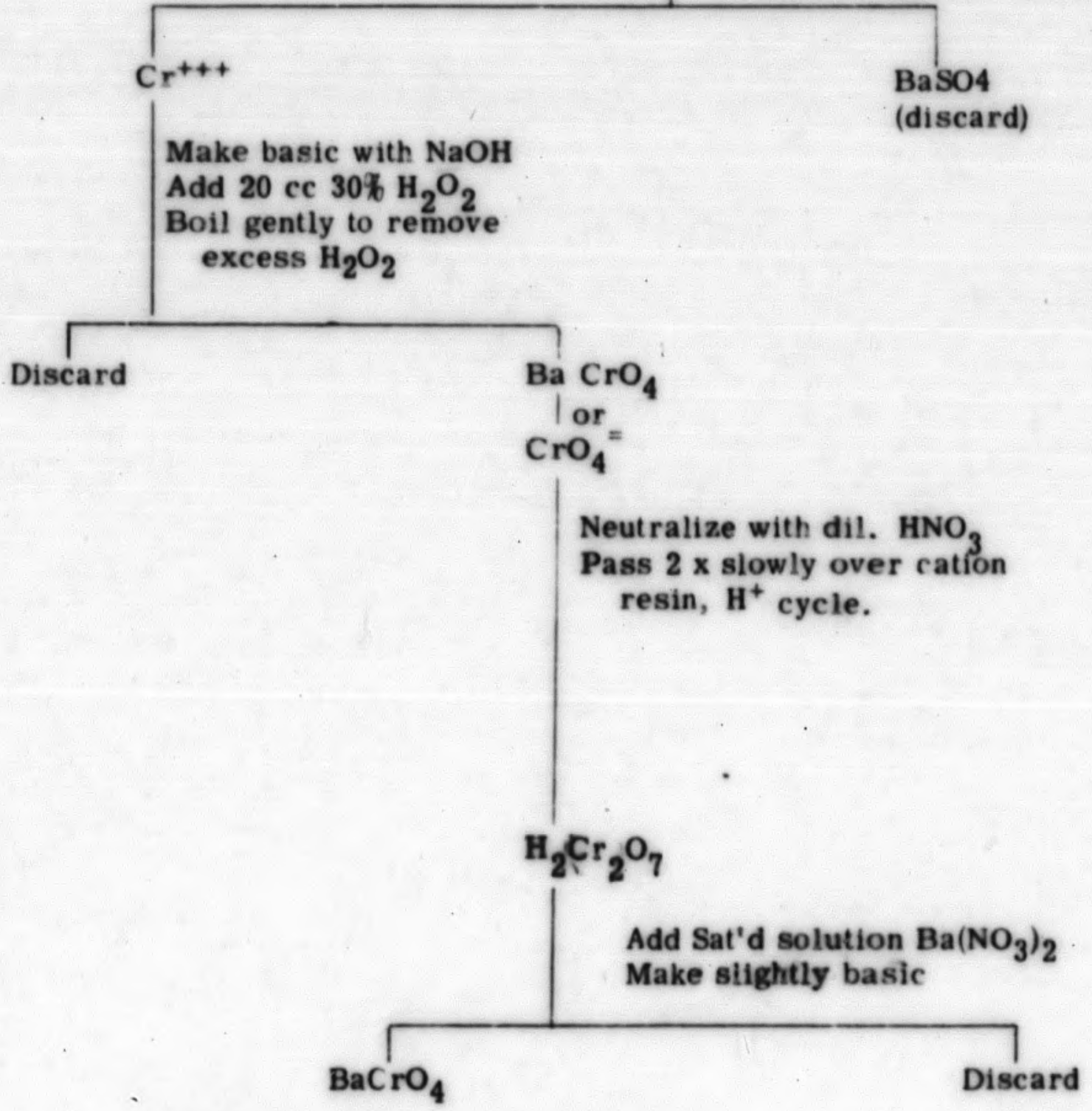

Mount on tared disc, weigh, and count. 
VII BIBLIOGRAPHY

1. Small, W. J., et al, "Long-Lived Circulating Activity in the Army Package Power Reactor", APAE-20, August 28, 1957.

2. Welinsky, I. н., "Water Technology Tests on STR Mark I", WAPD-STR-C-15, December 17, 1954.

3. Connalley, L., and Leboeuf, M. B., Anal. Chem., 25, 1095 (1953)

4. Schultz, B, , WAPD, personal communication.

5. Gilbert, R, S ., W APD, personal communication.

6. Gilbert, R. S., Oshorne, R. N., Grandy, G. L., Howard, E. R.,

"Radiochemical Analysis of the S-I-W Particulate Corrosion Products for the Period of Extended High Power Run", WAPD-ADC 61, December 3, 1356.

7. Ibid, pg. 8

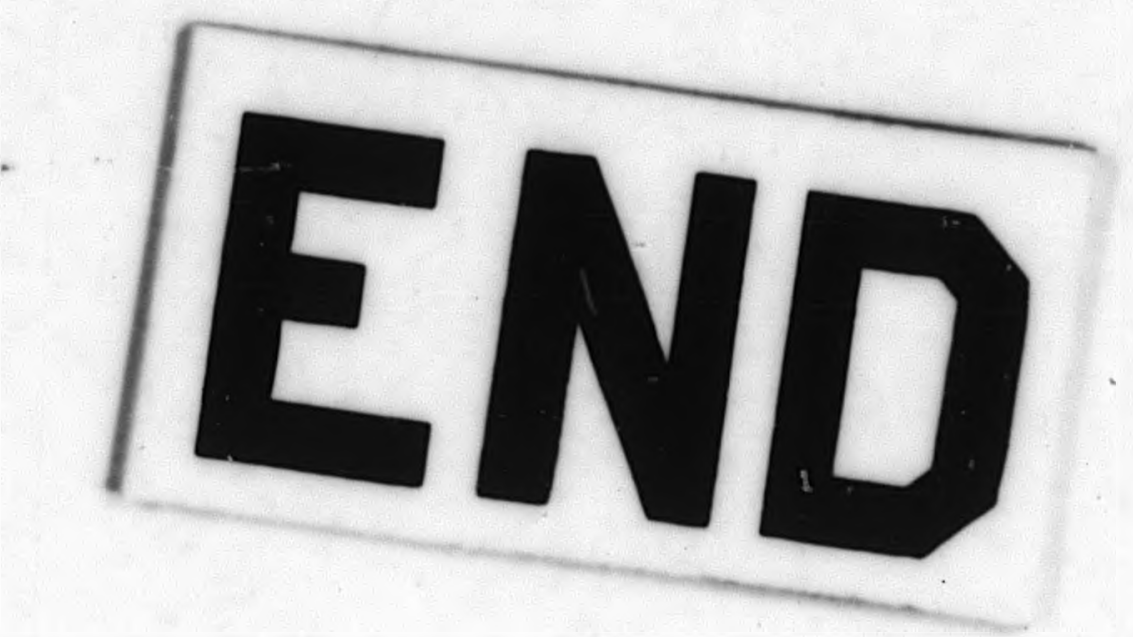

